\section{Research Square}

Preprints are preliminary reports that have not undergone peer review.

They should not be considered conclusive, used to inform clinical practice, or referenced by the media as validated information.

\title{
Method Shifting from Long to Short Term Contraceptives and its Associated Factors among Reproductive Age Women, Northwest Ethiopia, 2018
}

\section{Niguse Desalegn}

Metema Hospital, west Gondar Zone, Ethiopia

Yohannes Ayanaw Habitu ( $\nabla$ yohaneshabitu@gmail.com )

Department of Reproductive and child health, Institute of public health, college of medicine and health sceinces, University of Gondar, Gondar, Ethiopia https://orcid.org/0000-0002-9015-7428

Melaku Kindie Yenit

Department of Epidemiology and Biostatistics, Institute of Public health, University of Gondar, Ethiopia

Research note

Keywords: Method shifting, Contraceptives, Women, Ethiopia

Posted Date: August 21st, 2019

DOI: https://doi.org/10.21203/rs.2.13356/v1

License: (1) (i) This work is licensed under a Creative Commons Attribution 4.0 International License. Read Full License 


\begin{abstract}
Objective: Even if long term contraceptives are more effective, cost efficient and tolerable choices, method shifting from long to short term contraceptives continued as a global issue. Therefore this study assessed the proportion and associated factors of method shifting from long term to short term contraceptives in Gondar city administration, northwest Ethiopia.

Result: A total of 390 women participated in the study that made the response rate of the current study as $96 \%$. The overall proportion of method shifting from long to short term contraceptives was $48.5 \%$ with ( $95 \% \mathrm{Cl}: 43.8,53.3)$. Had secondary level educational status $(A O R=0.18,95 \% \mathrm{Cl} 0.07,0.51)$, had information about long acting contraceptives from friends $(A O R=6.67$, $95 \% \mathrm{Cl} 1.89,23.52)$, use of long acting contraceptives for limiting purposes (AOR=0.26, 95\% $\mathrm{Cl} 0.11,0.60$ ), and had enough counseling on long acting contraceptives during ANC visits $(A O R=0.20,95 \% \mathrm{Cl} 0.08,0.50)$ were found to have statistically significant association with method shifting.
\end{abstract}

\title{
Introduction
}

Method shifting is changing the choice of contraceptives from one group to another group, such as from LACM to short acting [1, 2]. During method shifting, women usually took time to decide the choice of contraceptives, which in turn exposed them for unintended pregnancy. In addition, some contraceptive methods may be new for women and they may need extra time to adapt the new method [3-6].

Evidence showed as long acting contraceptive methods (LACM) are more effective in preventing unintended pregnancy as compared to short acting ones [1, 3, 7]. In addition, short term contraceptive methods have an increased discontinuation rate as compared to LACM. Moreover, the rate of unplanned pregnancy and abortion is high among short term contraceptive users as compared to the LACM users due to high failure rate or miss use $[5,6,8]$.

A study conducted among IUCD users in Pakistan showed that 33.3\% of women shifted their method of choice to short term methods[8]. Another study done in Malawi showed that $58 \%$ of woman switched to more effective method, $24 \%$ switched to similarly effective methods and $18 \%$ switched to less effective methods [9]. A study in Lusaka, Zambia showed that among 145 implant users $13 \%$ shifted the methods, from these $89 \%$ shifted to short term family planning methods. And also of the $40 \%$ IUCD users $33 \%$ shifted the method, of these $92 \%$ shifted to short term family planning methods and $8 \%$ to Implanol [10]. Another similar study conducted in Kenya showed, $31.3 \%$ of woman shifted from LACM to short term contraceptives [11]. In addition, a study done in Honduran showed, $14 \%$ of IUCD users switched to other methods [12]. Furthermore, a study conducted by Marie stops by the year 2013 , showed $25 \%$ of contraceptive users shift their method choice from short term to LACM [13].

A study conducted in Dire Dawa showed, $40.4 \%$ of woman who use LACM shifted their method of choice, from these $29.8 \%$ from implants and 10.6\% from IUCD [3]. Another study done in Agarfa, Oromia region showed, method shifting from LACM to short term contraceptives was about $4.2 \%$, from this implant to injectables account for $3.4 \%$ and implant to pill $0.8 \%$ [14]. A study conducted in Jimma, showed among all contraceptive users $9.6 \%$ of them shifted to other methods within their first year of use. The highest 12 months shifting rate was observed for pills (19.9\%) followed by condom (12.4\%), while it was much lower for Implant (3.3\%) and IUD (5.1\%) [15].

\section{Ethiopia planned to achieve 55\% of Contraceptive Prevalence Rate (CPR) among reproductive age woman by 2020 . Of this LACM were planned to take $48 \%$ of all methods [16].}

The proportion of method shifting from LACM to short term contraceptives considerably vary from one study setting as compared to another setting. Similarly, factors associated with method shifting also vary from place to place. All the above evidences showed there is a need to conduct the current study in that specific context. Therefore, this study assessed the proportion of method shifting from LACM to short term contraceptive methods and its associated factors among reproductive age women in Gondar city administration, northwest Ethiopia.

Page 2/11 


\section{Methods}

\section{An institution based cross-sectional study was conducted from February to June 2018, at health facilities found in Gondar city [17].}

Reproductive age women, who live in Gondar city and came to the health centers for removal of LACM or shift to short term and who had follow up visits of LACM were included in the study. Women who were severely ill or unable to respond were excluded. Study subjects were selected using systematic random sampling technique. Sample size was determined using single population proportion formula, considering the following assumptions: $40.4 \%$ as proportion $(\mathrm{P})$ of woman who shift their method of choice from long to short term contraceptives [3], $95 \%$ confidence level and $5 \%$ degree of precision and 10\% non-response rate. Finally, the sample size calculated for the study was 407.

Method shifting is defined as the altering of previous choice of contraceptives, LACM to short term methods. That is from implant to any short term methods within three years of insertion and from IUCD to any short term methods within five years of insertion.

Data were collected by using a pre-tested, structured, and interviewer-administered questionnaire. Data were entered into Epi-info version 7 soft ware, and then it was exported to the Statistical Package for Social Sciences (SPSS) soft ware version 20. The data were checked for completeness, cleaned, coded and for further analyzed using SPSS. Descriptive statistics were carried out for each of the variables and to ascertain the proportion of woman who shifted their method of choice. Then, findings were summarized and presented by frequency tables and charts. Adjusted odds ratios with $95 \%$ confidence intervals (Cl) and P-Value less than 0.05 were taken as statistically significant.

\section{Results}

\section{Socio-demographic characteristics of the respondents}

A total of 390 women participated in the study that made the response rate of the current study as $96 \%$. The majority of the respondents, 315(80.8\%), were urban residents; while one-third, 148(37.9\%), of the respondents were uneducated. Concerning the age of the respondents, the majority, 139(35.6\%), ranged between18-24 years, with the mean age of 27 years and a standard deviation (SD) of \pm 6.4 (Table1)..

Regarding the source of information, more than half, 222 (56.9\%), of them get information about contraceptive methods from health care providers. Moreover, about $14.4 \%$ of them revealed that counseling service provided at health institution was not adequate (Table 2)..

\section{Factors associated with method shifting}

Two models called the bivariable and multivariable logistic analysis were carried out to identify factors associated with the outcome variable. In the bi-variable logistic regression analysis; age, educational status, counseling about LACM during ANC visit, reason for family planning use, previous number of children, demand of children, counseling satisfaction during family planning service, marital status, experience of pregnancy while using modern family planning, information about LACM were eligible factors found to have significant association(having $p$-value of less than 0.2 ) with method shifting. All of those variables having P-value of $<0.2$ in the bivariable analysis were fitted in to the multivariable logistic regression model. Had secondary educational level, got information about LACM from friends, contraceptive use for limiting and get counseling from providers during ANC visits were found to be significant factors associated with method shifting at p-value of less than 0.05 .

The odds of method shifting was $83 \%$ less likely to occur among women who had secondary educational level as compared to those women who were uneducated $(A O R=0.17 ; 95 \% \mathrm{Cl} 0.06,0.45)$. The odds of method shifting was $75 \%$ less likely to occur among women who used LACM for limiting as compared to those women who used for spacing $(\mathrm{AOR}=0.25 ; 95 \% \mathrm{Cl} 0.11,0.56)$. The odds of method shifting was 6.67 times more likely to occur among women who get information about LACM from friends as compared to those who get information from health providers ( $A O R=6.65 ; 95 \% \mathrm{Cl} 1.92-23.02)$. The odds of method shifting 
was $78 \%$ lower as compared to those women who did not get got adequate counseling during ANC visit $(\mathrm{AOR}=0.22 ; 95 \% \mathrm{Cl}$ $0.09,0.51$ ) (Table 3)..

\section{Reproductive history of the respondents}

More than half, 234(60\%), of women started first sexual intercourse at age before 18 (mean age 17.9, SD \pm 2.8 ) and about $186(53.4 \%)$ of women married before the age of 18 years. In addition, nearly half of the respondents, $139(48.4 \%)$, had history 1-2 pregnancies. Moreover, one-fifth, $72(23.5 \%)$, of the women had history of home delivery. Nearly half, $147(47.9 \%)$ of the women attended antenatal care at least once (Additional file 1: Table S1)..

\section{Proportion of Method shifting}

Nearly half, $113(48.5 \%$ ) (With 95\% Cl: 43.8-53.3), of respondents had shifted from LACM to short term contraceptive methods. Method shifting from implant to other short term contraceptive methods was $34 \%$ and shifting from IUCD was $14.5 \%$. More than a third, 76(37.1\%), shifted their previous method between 6 and 12 months. More than one-fifth (25.9\%) of women shifted the contraceptive within the first six months of insertion (Additional file 2: Figure S1)..

\section{Additional file 2: Figure S1: Time of Method shifting from long to short family planning methods}

Forty four (11\%) of women reported that they were pregnant while using modern contraceptive methods such as DEPO, 23(5.9\%), and pills, 15(3.8\%).The main reasons for method shifting were side effects 176 (87.14\%) such as bleeding, weight loss and feeling of numbness (Additional file 3: Figure S2)..

\section{Additional file 3: Figure S2: Reasons for Method shifting from long to short term contraceptive methods.}

\section{Discussion}

\section{In this study, the proportion and factors associated with method shifting from LACM was assessed. The proportion of method shifting was $48.5 \%$ with $95 \% \mathrm{Cl}(43.8,53.3)$.}

The finding was in line with the study conducted in Egypt 46\%[20]. This finding was lower as compared with those studies conducted in Vietnam $80 \%[21]$ Malawian 58\% [9], Zambia 89\% [10], and Vietnam 66.7\%[22]. The possible justification might be due to the fact that Ethiopian government has given more emphasis for LACM use, through nurses, midwives and health extension programs even at lower level of the health care system (primary health care unit). Moreover, variations in study subjects among studies might be the possible justification for the differences. For instance, only post-partum women were included in Malawi and HIV concordant positive or discordant couples were study participants included in Zambia.

This finding was lower in studies conducted in Kenya (31.3\%) [11], Pakistan (33.3\%) [8], Agarfa, Oromia region (4.2\%) [14], Dire Dawa (40.4\%) [3]. This might be due to differences in selection of study subjects and variation in some socio demographic characteristics between studies. For instance, $91 \%$ of participants in the study conducted in Dire Dawa were married, while $76 \%$ of women in the current study were single. As a result, married women might be less likely shift their method of choice from LACM as compared to single women.

The odds of method shifting among women who had secondary education was $83 \%$ less as compared with uneducated women $(A O R=0.17: 95 \% \mathrm{Cl} 0.06,0.45)$. This finding was consistent with other studies done in Dire Dawa and Senegal $[3,21,23]$. This might be because women who were educated get information on LACM. 
The odds of method shifting was $75 \%$ less likely among women who used contraceptives for limiting as compared to women who used for spacing(AOR $=0.25 ; 95 \% \mathrm{Cl} 0.11,0.56)$. This finding was consistent with those studies done in Dire Dawa, Jimma and Hossana[3], $[15,19]$. This might be because women who use LACM for limiting may reached their desired family size, decide to have no more children for future.

The odds of method shifting among women who get information about LACM from friends were 6.65 times more likely to occur as compared to women who get information from health care providers ( $A O R=6.65 ; 95 \% \mathrm{Cl} 1.92,23.02)$. This finding was consistent with those studies done in Dire Dawa[3]. This might be due to the fact that women who get information from friends may not get tangible information; the information from friends may be full of misconceptions, myths and false believes.

The odds of method shifting was $78 \%$ less likely among women who get counseling about LACM during ANC follow up compared to those didn't get counseling $(A O R=0.22 ; 95 \% \mathrm{Cl} 0.09,0.51)$. This finding was consistent with the study conducted in Jimma town [15]. This might be because women who attend all ANC follow up will get counseling about LACM during the course of ANC follow-up to get adequate information about LACM.

As a conclusion, method shifting was moderate compared to previous studies. Educational status, got information from health care providers, use of LACM for limiting purposes, and had enough counseling on LACM during ANC visits were found to have statistically significant association with method shifting. Therefore, improving women's educational status, providing proper information about LACM through health care providers and provision of enough counseling about LACM during ANC visits are strongly recommended.

\section{Limitations}

The cross-sectional nature of the study design might have prevented the work from showing temporal relationships. In addition, the study did not consider the role of husband in contraceptive method utilization.

\section{Abbreviations}

AOR: Adjusted Odds Ratio; Cl: Confidence Interval; COR: Crude Odds Ratio; CPR: Contraceptive Prevalence Rate; EDHS: Ethiopian Demographic Health Survey; FGA: Family Guidance Association; IMP: Implant; IUCD/IUD: Intra Uterine Contraceptive Device; LACM: Long Acting Contraceptive Methods: SPSS: Statistical Package for Social Sciences

\section{Declarations}

\section{Ethics approval and consent to participate}

Ethical clearance was obtained from the Institute Review Board (IRB) of the Institute of Public Health, University of Gondar. A letter of permission was obtained from the respective health facilities. After the objective of the study was explained, verbal and written consent was obtained from each participant. The right of participants to withdraw from the study at any time without any precondition was provided. Moreover, the confidentiality of information obtained was guaranteed by using code numbers rather than personal identifiers and by keeping the questionnaire locked.

\section{Consent to publish}

\section{Not applicable.}

\section{Availability of data and materials}


All the data required to make the conclusions of the results of this study are included in the manuscript and as additional files.

\section{Competing interests}

The author declared that there have no competing interests.

\section{Funding}

No funding was obtained for this study.

\section{Authors' contributions}

ND, YAH and MKY conceived the study. ND coordinated the data collection. ND, YAH and MKY performed statistical analysis and drafted the manuscript. All authors read and approved the final manuscript.

\section{Acknowledgments}

The authors of this manuscript would like to acknowledge all staff who work in Gondar city health centers, especially who work on family planning departments. The authors also want to acknowledge the study participants, the data collectors, and the supervisor for their commitment to take part in the study.

\section{References}

1.Taye A, Woldie M, Sinaga M: Predictors of Long Acting Reversible Contraceptive use among Married Women Visiting Health Facilities in Jimma Town. Women's Health Care 2017, 4(1).

2.Tibaijuka L, Odongo R, Welikhe E, Mukisa W, Kugonza L, Busingye I, Nabukalu P, Ngonzi J, Asiimwe SB, Bajunirwe F: Factors influencing use of long-acting versus short-acting contraceptive methods among reproductive-age women in a resource-limited setting. BMC Women's Health 2017, 17(25):13.

3.Atnafe M, Assefa N, Alemayehu T: Long-acting family planning method switching among revisit clients of public health facilities. Contraception and Reproductive Medicine 2016, 1(18).

4.Khalifa M, Abdelaziz W, Sakr E: Changes in Contraceptive Use Dynamics in Egypt: Analysis of the 2008 and 2014 Demographic and Health Surveys. In.; 2017.

5.HEALTH GORMO: FAMILY PLANNING STRATEGIC PLAN. In.; 2012-2016. 
6.Yalew SA, Zeleke BM, Teferra AS: Demand for long acting contraceptive methods and associated factors among family planning service users, Northwest Ethiopia. BMC Research Notes 2015, 8(29).

\section{Alvergne A, Stevens R, Gurmu E: Side effects and the need for secrecy: characterising discontinuation of modern contraception and its causes in Ethiopia using mixed methods. bioRxiv preprint2017.}

8.Hameed W, Azmat SK, Ali M, Hussain W, Mustafa G, Ishaque M, Ali S, Ahmed A, Temmerman M: Determinants of Method Switching among Social Franchise Clients Who Discontinued the Use of Intrauterine Contraceptive Device. International Journal of Reproductive Medicine 2015:8.

9.Kopp DM, Rosenberg NE, Stuart GS, Miller WC, Hosseinipour MC, Bonongwe P, Mwale M, Tang JH: Patterns of Contraceptive Adoption, Continuation, and Switching after Delivery among Malawian Women. PLOS ONE 2017, 12(1).

10.Lisa Haddad M, MS, MPH, Kristin M Wall P, Bellington Vwalika M, M.MED,, MSc, Naw Htee Khu M, Ilene Brill M, William Kilembe M, MSc, Rob, Stephenson P, Elwyn Chomba M, DCH et al: Contraceptive discontinuation and switching among couples receiving integrated HIV and family planning services in Lusaka, Zambia. NIH Public Access Author Manuscript 2014, 27(01):S95-103.

\subsection{AS, Mbondo M, Joyce W, Susan K, Amy H-R, Christine O: Family Planning Method Switch and Discontinuation among Women aged 15-24 years in Kenya. 2012.}

12.Barden-O'Fallon J, Speizer I: What differentiates method switchers from discontinuers? An examination of contraceptive discontinuation and switching among Honduran women. Int Perspect Sex Reprod Health 2014, 37(1):16-23.

13.Nuccio O, Reichwein B: Understanding clients and achieving FP2020 goals: Exit interviews help deliver client-centred services. Research brief series Marie Stopes International 2013, 006.

\section{Bekele T, Gebremariam A, Tura P: Contraceptive Choice and Switching Pattern among Married Women in Rural Community of South East Ethiopia. Family Medicine \& Medical Science Research 20143, 3(3).}

15.Yideta ZS, Mekonen L, Seifu W, Shine S: Contraceptive Discontinuation, Method Switching and Associated Factors among Reproductive Age Women in Jimma Town, Southwest Ethiopia. Fam Med Med Sci Res 2017, 6(1).

\section{HEALTH MO: COSTED IMPLEMENTATION PLAN FOR FAMILY PLANNING IN ETHIOPIA, 2015/16-2020. In. Adiss Abeba: Ministry of Health; 2016.}

17.Zenebe K, Mekonen B: Utilization and Associated Factors of Modern Contraceptive among Women Attending Art Clinics in Gondar Town, Northwest Ethiopia. Scholars Journal of Applied Medical Sciences (SJAMS) 2014, 2(((5F)).

18.Shiferaw K, Musa A: Assessment of utilization of long acting reversible contraceptive and associated factors among women of reproductive age in Harar City, Ethiopia. Pan African Medical Journal 2017, 28(222).

19.Earsido A, Gebeyehu A, Kisi T: Determinants of Long Acting and Permanent Contraceptive Methods Utilization among Married Women in Hossana Town, Southern Ethiopia: A Case - Control Study. Preg Child Health 2015, 2(3). 
20.Khalifa M, Abdelaziz W, Sakr E: EGYPT DEMOGRAPHIC AND HEALTH SURVEYS. 2017, 132.

\section{Castle S, Askew I: CONTRACEPTIVE DISCONTINUATION: REASONS, CHALLENGES, AND SOLUTIONS. Ideas, Evidence, Impact 2015.}

22.Park MH, Nguyen TH, Ngo TD: Dynamics of IUD use in Vietnam: implications for family planning services at primary health care level. International Journal of Women's Health 2011, 3.

23.Barden-O'Fallon J, Speizer IS, Calhoun LM, Corroon M: Women's contraceptive discontinuation and switching behavior in urban Senegal, 2010- 2015. BMC Women's Health 2018, 18(35).

\section{Tables}

Table 1: Socio-demographic characteristics of women of reproductive age in health facilities of Gondar City, 2018

\begin{tabular}{|c|c|c|}
\hline Variables & Frequency & Percent \\
\hline \multicolumn{3}{|c|}{ Age of the women (in year) } \\
\hline $18-24$ & 139 & 35.6 \\
\hline $25-29$ & 138 & 35.4 \\
\hline $30-34$ & 51 & 13.1 \\
\hline \multirow{2}{*}{\multicolumn{3}{|c|}{ Place of residence }} \\
\hline & & \\
\hline Urban & 315 & 80.8 \\
\hline \multirow{2}{*}{\multicolumn{3}{|c|}{ Educational status }} \\
\hline & & \\
\hline Uneducated & 148 & 37.9 \\
\hline Elementary (1-8) & 102 & 26.2 \\
\hline Secondary (9-12) & 98 & 25.1 \\
\hline Diploma and above & 42 & 10.8 \\
\hline \multicolumn{3}{|l|}{ Marital status } \\
\hline Married & 305 & 78.2 \\
\hline Divorced & 23 & 5.9 \\
\hline Widowed & 11 & 2.7 \\
\hline Single & 51 & 13.2 \\
\hline \multicolumn{3}{|l|}{ Religion } \\
\hline Orthodox Christian & 298 & 76.4 \\
\hline Muslim & 82 & 21.1 \\
\hline Others $^{1}$ & 10 & 2.5 \\
\hline \multicolumn{3}{|l|}{ Ethnicity } \\
\hline Amhara & 299 & 76 \\
\hline Muslim & 70 & 18 \\
\hline Others ${ }^{2}$ & 21 & 6 \\
\hline \multicolumn{3}{|l|}{ Employment status } \\
\hline Student & 77 & 19.7 \\
\hline Merchant & 53 & 14.1 \\
\hline Daily laborer & 15 & 3.5 \\
\hline House wife & 173 & 44.3 \\
\hline Government employee & 50 & 12.7 \\
\hline Others $^{3}$ & & \\
\hline
\end{tabular}


${ }^{1}$ protestant, catholic, ${ }^{2}$ Oromo, ${ }^{3}$ Farmer

Table 2: Contraceptive history of women of reproductive age who were using health facilities in Gondar city, northwest Ethiopia, 2018

\begin{tabular}{lll}
\hline Variables & Frequency & Percent \\
\hline Reason of family planning use & & 59 \\
Birth spacing & 230 & 41 \\
Birth limiting & 160 & 59.5 \\
Over all method shifting & 232 & 40.5 \\
Yes & 158 & 48.5 \\
No & & 52.5 \\
Method shifting from long to short term contraceptives & 113 & 11 \\
Yes & 119 & 89 \\
No & & \\
Yes & 44 & 59.7 \\
No & 346 & 19.7 \\
Source of information for long acting contraceptive & & 18.2 \\
Health facility & 233 & 2.4 \\
Media & 77 & 81 \\
Others & 9 & 14.4 \\
Sounseling service at the health facility & 9 & 334 \\
Not-satisfied & 56 & \\
\hline
\end{tabular}

Table 3: Factors associated with method shifting from long acting family planning method among women of reproductive age in Gondar city, northwest Ethiopia, 2018. 


\begin{tabular}{|c|c|c|c|c|}
\hline \multirow[t]{3}{*}{ Variables } & \multicolumn{2}{|c|}{ Method shifting } & \multirow{3}{*}{$\begin{array}{l}\text { Crude Odds } \\
\text { Ratio } \\
{[95 \% \text { CI }]}\end{array}$} & \multirow{3}{*}{$\begin{array}{l}\text { Adjusted Odds Ratio } \\
{[95 \% \mathrm{CI}]}\end{array}$} \\
\hline & Yes & No & & \\
\hline & $\mathrm{N}(\%)$ & $\mathrm{N}(\%)$ & & \\
\hline \multicolumn{5}{|l|}{$\begin{array}{l}\text { Age of } \\
\text { Nomen (in } \\
\text { rears) }\end{array}$} \\
\hline & $72(35.8 \%)$ & $76(40.2 \%)$ & 1 & 1 \\
\hline $25-29$ & $63(31.3 \%)$ & $71(37.6 \%)$ & $\begin{array}{l}1.07(0.67- \\
1.71)\end{array}$ & $1.82(0.71-4.65)$ \\
\hline $30-34$ & $28(13.9 \%)$ & 19(10.1\%) & $\begin{array}{l}0.64(0.33- \\
1.25)\end{array}$ & $1.13(0.31-4.06)$ \\
\hline Above 35 & $38(18.9 \%)$ & $23(12.2 \%)$ & $\begin{array}{l}0.57(0.31- \\
1.06)\end{array}$ & $0.57(0.31-1.06)$ \\
\hline \multicolumn{5}{|l|}{$\begin{array}{l}\text { Educational } \\
\text { status }\end{array}$} \\
\hline Jneducated & $69(34.3 \%)$ & $79(41.8 \%)$ & 1 & 1 \\
\hline Elementary & $42(20.9 \%)$ & $60(31.7 \%)$ & $\begin{array}{l}1.25(0.75- \\
2.08)\end{array}$ & $1.06(0.35-6.69)$ \\
\hline S̄econdary & $65(32.3 \%)$ & $33(17.5 \%)$ & $\begin{array}{l}0.44(0.26- \\
0.75)\end{array}$ & $0.18(0.07-0.51) *$ \\
\hline $\begin{array}{l}\text { Jiploma and } \\
\text { above }\end{array}$ & $25(12.4 \%)$ & $17(9 \%)$ & $\begin{array}{l}0.59(0.30- \\
1.19)\end{array}$ & $0.95(0.25-3.57)$ \\
\hline \multicolumn{5}{|l|}{$\begin{array}{l}\text { Marital } \\
\text { status }\end{array}$} \\
\hline Married & $163(81.1)$ & $143(75.7)$ & 1 & 1 \\
\hline Single & $25(12.4)$ & $20(10.6)$ & $\begin{array}{l}0.912(0.49- \\
1.71)\end{array}$ & $\begin{array}{l}1.878(0.12- \\
29.37)\end{array}$ \\
\hline Jthers & $13(6.5)$ & 26 (13.8) & $\begin{array}{l}2.280(1.13- \\
4.60)\end{array}$ & $3.704(0.60-23.02)$ \\
\hline \multicolumn{5}{|l|}{$\begin{array}{l}\text { Number of } \\
\text { Jregnancy }\end{array}$} \\
\hline $1-2$ & 49(33.3\%) & $76(54.3 \%)$ & 1 & 1 \\
\hline $3-4$ & $75(51 \%)$ & $50(35.7 \%)$ & $\begin{array}{l}0.43(0.26- \\
0.71)\end{array}$ & $0.32(0.13-0.75)$ \\
\hline Above 5 & $23(15.6 \%)$ & $14(10 \%)$ & $\begin{array}{l}0.39(0.18- \\
0.84)\end{array}$ & $0.25(0.06-1.12)$ \\
\hline \multicolumn{5}{|l|}{$\begin{array}{l}\text { Number of } \\
\text { shildren }\end{array}$} \\
\hline 1 & $53(35.8)$ & $57(40.1 \%)$ & 1 & 1 \\
\hline $2-4$ & $79(53.4 \%)$ & $82(57.7 \%)$ & $\begin{array}{l}0.97(0.59- \\
1.57)\end{array}$ & $0.82(0.34-1.94)$ \\
\hline Above 5 & $16(10.8 \%)$ & $3(2.1 \%)$ & $\begin{array}{l}0.17(0.05- \\
0.63)\end{array}$ & $0.12(0.01-0.96)$ \\
\hline \multicolumn{5}{|l|}{$\begin{array}{l}\text { Number of } \\
\text { shildren to } \\
\text { lave }\end{array}$} \\
\hline $1-2$ & $113(56.8 \%)$ & 133(70.7\%) & 1 & 1 \\
\hline $3-4$ & 67(33.7\%) & $44(23.4 \%)$ & $\begin{array}{l}0.56(0.35- \\
0.88)\end{array}$ & $0.85(0.36-2.02)$ \\
\hline Above 5 & $19(9.5 \%)$ & $11(5.9 \%)$ & $\begin{array}{l}0.49(0.23- \\
1.08)\end{array}$ & $0.77(0.18-3.27)$ \\
\hline \multicolumn{5}{|l|}{$\begin{array}{l}\text { Have you } \\
\text { כxperience } \\
\text { oregnancy } \\
\text { while using } \\
\text { on Family } \\
\text { Jlanning }\end{array}$} \\
\hline Yes & $16(8.0 \%)$ & $28(14.8 \%)$ & $\begin{array}{l}2.01(1.05- \\
3.85)\end{array}$ & $4.31(0.74-25.26)$ \\
\hline
\end{tabular}




\begin{tabular}{|c|c|c|c|c|}
\hline $\begin{array}{l}\text { No } \\
\text { Jot enough } \\
\text { zounseling } \\
\text { on long term } \\
\text { zontraceptive } \\
\text { luring ANC } \\
\text { Jisit }\end{array}$ & $185(92 \%)$ & $161(85.2 \%)$ & 1 & 1 \\
\hline Yes & $44(49.4 \%)$ & $45(50.6 \%)$ & $\begin{array}{l}0.35(0.18- \\
0.65)\end{array}$ & $0.20(0.08-0.50)^{*}$ \\
\hline $\begin{array}{l}\text { No } \\
\text { Have you } \\
\text { satisfied on } \\
\text { Adequate } \\
\text { zounseling } \\
\text { luring family } \\
\text { ?lanning }\end{array}$ & $23(25.3)$ & $68(74.8 \%)$ & 1 & 1 \\
\hline Yes & 178(88.6\%) & 156(82.5\%) & $\begin{array}{l}0.61(0.34- \\
1.09)\end{array}$ & 0.59(0.18-1.88) \\
\hline $\begin{array}{l}\text { No } \\
\text { Reasons for } \\
\text { :amily } \\
\text { planning use }\end{array}$ & $23(11.4 \%)$ & $33(17.5 \%)$ & 1 & 1 \\
\hline Birth limiting & $95(47.3 \%)$ & $65(34.4 \%)$ & $\begin{array}{l}0.59(0.39- \\
0.88)\end{array}$ & $0.26(0.11-0.60)^{*}$ \\
\hline $\begin{array}{l}\text { Pregnancy } \\
\text { spacing } \\
\text { Jource of } \\
\text { nformation } \\
\text { tbout long } \\
\text { :erm family } \\
\text { Jlanning }\end{array}$ & 106(52.7\%) & $124(65.6 \%)$ & 1 & 1 \\
\hline $\begin{array}{l}\text { Health } \\
\text { :acility }\end{array}$ & 142(70.6\%) & $91(48.1 \%)$ & 1 & 1 \\
\hline Friends & 39 (19.4\%) & $38(20.1 \%)$ & $\begin{array}{l}2.28(1.28- \\
4.06)\end{array}$ & $6.67(1.89-23.52) *$ \\
\hline $\begin{array}{l}\text { Media } \\
\text { 'others } \\
\end{array}$ & $20(10 \%)$ & $60(31.8 \%)$ & $\begin{array}{l}2.16(1.04- \\
4.47)\end{array}$ & $2.31(0.51-9.76)$ \\
\hline
\end{tabular}

*Found statistical significant at p-value $\leq 0.05$

\section{Supplementary Files}

This is a list of supplementary files associated with this preprint. Click to download.

- Additionalfile3FigureS2.docx

- Additionalfile2FigureS1.docx

- Additionalfile1Tables1.docx 